10 Britt.BA, Kalow W. Malignant hyperthermia: aetiology unknown. Can Anaesth Soc J 1970; 17: 316-30.

11 Brozek J, Grande F. Body composition and basal metabolism in man: correlation analysis versus physiological approach. Hum Biol 1956; 27: 22-31.

12 Sjogaard $G$, Kiens B, Jorgensen $K$, Saltin B. Intramuscular pressure, EMG and blood flow during low-level prolonged static contraction in man. Acta Physiol Scand 1986; 128: 475-84.

\section{Metallic microparticles in the needle-through-needle technique}

To the Editor:

Eldor attempted to lay the blame for two cases of aseptic meningitis following regional anaesthesia on metal particles that formed because of the needlethrough-needle combined spinal-epidural technique. ${ }^{1}$ $\mathrm{He}$ quoted our investigation of the formation of metallic particles when we passed pencil-point needles over the curved orifice of Tuohy or Hustead epidural needles $^{2}$ to support his argument. In fact, we found similar notching at the tip of epidural needles that Eldor reported in his original letter. ${ }^{3}$ However, he neglected to state that we did not find metal particles after needle-through-needle passage that he espouses to explain this notching defect. Our report and that of another ${ }^{4}$ contradict his contentions.

Until Eldor can provide substantial evidence for the existence of microparticles, beyond the ones we found on every freshly opened, unused Tuohy needle inspected in our study, he should not be given an unrefereed forum to express unsupported claims.

Norman L. Herman MD PhD

Director, Obstetric Anesthesia Research

New York Hospital-Cornell University Medical College Department of Anesthesiology

525 E. 68th Street New York, NY 10021, USA

\section{REFERENCES}

1 Eldor J. Aseptic meningitis using the needle-throughneedle technique (Letter). Can J Anaesth 1996; 43: 1183-4

2 Herman N, Molin J, Knape KG. No additional metal particle formation using the needler through-needle combined epidural/spinal technique. Acta Anaesthesiol Scand 1996; 40: 227-31.

3 Eldor J, Brodsky V. Danger of metallic particles in the spinal-epidural spaces using the needle-through-needle approach (Letter). Acta Anaesthesiol Scand 1991; 35: 461.
4 Hargreaves J. Metal particle generation caused by the combined spinal-extradural technique (Letter). Br J Anaesth 1993; 70: 706.

\section{REPLY}

I thank Dr. Herman and his group for their continuous interest in my 1991 observation that the needlethrough-needle technique produces metallic microparticles. However I need to clarify some facts related to Dr. Herman's article:

$A$ "notching defect" is a notching defect. That they did not detect metal filings or chips in either flush solutions does not mean they were not there. They bave progressed from "No metal particle contamination" $"$ ", to "No additional metal particle formation. ${ }^{01,3}$

Dr. Herman is mixing two things: His "notching defect" is evidence of friction between the spinal needle and the bent epidural needle tip in the needle-through-needle technique. It is another whether these metallic micropaticles cause or serpe as a nidus for aseptic meningitis.

Joseph Eldor MD

Jerusalam, Israel

\section{REFERENCES}

1. Eldor J. Metallic microparticle formation using the needlethrough-needle technique (Letter). Acta Anaesthesiol Scand 1997; 41: 326-7.

2. Molin JD, Knape KG, Herman NL, Husain FJ. No metal particle contamination of epidural or subarachnoid spaces using needle-through-needle techniques. Anesthesiology 1992; 77: Al031.

3. Herman N, Molin J, Knape KG. No additional metal particle formation using the needle-through-needle combined epidural/spinal technique. Acta Anaesthesiol Scand 1996; 40: 227-31.

\section{Persistent intraoperative myoclonus during propofol-fentanyl anaesthesia}

To the Editor:

A 63-yr-old otherwise healthy man presented for shoulder surgery. Three minutes after induction of anaesthesia with $1 \mathrm{\mu g} \cdot \mathrm{kg}^{-1}$ fentanyl and $2 \mathrm{mg} \cdot \mathrm{kg}^{-1}$ propofol, the patient developed myoclonic jerking of his legs. These spasmodic contractions persisted for the next $10 \mathrm{~min}$, during which propofol was infused at $6 \mathrm{mg} \cdot \mathrm{kg}^{-1} \cdot \mathrm{hr}^{-1}$. Because there were no changes in nature of the myoclonic movements, propofol was discontinued and $10 \mathrm{~min}$ later, the patient was fully awake and the myoclonic movements completely disappeared. 